\title{
Editorial
}

\section{Governmental impacts and information availability}

We have written and lectured extensively [1-3] on the role of government in positive actions for the benefit of science and technology information access and distribution. On occasion, we have decried negative actions from this sector.

Not so long ago we were made aware of a negative series of events that illustrate how well meaning governmental participation in information product formation can override even the best intentioned efforts.

Many of our readers are aware of the excellent service provided to information users and libraries by the International Translations Centre (ITC) located in Delft, The Netherlands. ITC collects and disseminates data on the world's scientific translations. The service acts primarily as a clearinghouse for information that points to the existence and whereabouts of translated material. ITC is a not-for-profit foundation operating as a non-governmental organization.

It is necessary to emphasize the international nature of this work. In 1953 the lead was taken in this area by the U.S. National Translations Center (NTC). In 1961, the ITC was established to work in the closest cooperation with the NTC. Indeed the NTC was one of the founding members of ITC and was represented on its board at various times.

Until 1988, ITC worked in collaboration with the NTC, then located at the University of Chicago's John Crerar Library. In that year the U.S. Library of Congress visited ITC and a series of events too complex to be reported here, ensued. The end result was the termination of the NTC at Crerar, with the Library of Congress assuming the collection roles for U.S. translations. ITC continued its work on indexing the material and assumed the input function for the formation of the World Translations Index (WTI) previously filled by the NTC.

It is important for the user community to understand that the WTI database was the vehicle for the delivery of translations. ITC entered the bibliographic data on the understanding that $\mathrm{LC}$ would provide the document delivery.

On September 30, 1993 the Library of Congress closed NTC operations following prolonged negotiations with ITC to prevent the loss of this important information. The whole collection of NTC material from 1961-1993 indexed by ITC is now unavailable. It must be understood that ITC did not approach the situation with empty hands. As a participant in the ITC network, the British Library Document Supply Centre (BLDSC) volunteered to house the NTC collection and the Canada Institute 
for Scientific and Technical Information (CISTI) offered to take over the collection indexed by NTC/LC (1989-1993). Other U.S. sources also indicated their interest in housing the information.

Several American organizations and individuals (including this editor) attempted to interpose in this sad scenario without effect. It is our understanding that communications between ITC and the Library of Congress have broken down and that a severe interruption in the bibliographic control work required to provide this critical body of cost-saving information has been encountered.

We would be pleased to offer the Library of Congress space in these pages to make any response explaining this development. In the meantime we urge our readers to seize any opportunity to present their feelings to the Library and the U.S. Congress.

\section{References}

[1] The NFAIS Yearbook of the Information Industry (1992): 1-4, Learned Information Inc., Medford, NJ, USA.

[2] The NFAIS Yearbook of the Information Industry (1993): 107-111, Learned Information Inc., Medford, NJ, USA.

[3] Navigating the Information Matrix, an Industry Overview, presented at Division of Chemical Information, American Chemical Society, August 23, 1994. 